Gut, 1961, 2, 252

\title{
The cardiac sphincter in the cat
}

\author{
C. G. CLARK ${ }^{1}$ and J. R. VANE
}

From the Department of Pharmacology, Royal College of Surgeons of England, London

SYNOPSIS A study of the function of the lower end of the oesophagus in the cat confirms that it behaves as a true physiological sphincter, even though histological evidence for such a structure is absent. Sphincteric action is a function of the circular muscle fibres in the lowest $2 \mathrm{~cm}$. of the oesophagus. Reflex changes in tone of the sphincter are mediated through the autonomic nervous system.

The effects of possible neurohumoral transmitters, nerve stimulation, and antagonists have been studied.

In some laboratory animals (guinea-pig, rabbit, hamster, rat, mouse) a well-delineated anatomical sphincter at the cardia has been described, whereas in others (monkey, dog, and cat) the sphincter cannot be clearly defined by histological techniques (Botha, 1958a). Nevertheless, it is generally accepted that even though histological evidence is lacking, a sphincteric mechanism exists in these animals. Cannon (1908), Carlson, Boyd, and Pearcy (1922), and Knight (1934) all obtained physiological evidence for a sphincter in the cat, although different interpretations of the function, control, and exact location of the mechanism have been suggested. For instance, Nauta (1956) suggested that the sphincter acted only as a valve (in the dog) to prevent gastric reflux, and this interpretation has also been suggested for man (Barrett, 1954; Dornhorst, Harrison, and Pierce, 1954; Nauta, 1955, 1956), in whom the histological evidence for a sphincter is also lacking (Lendrum, 1937; Roux, 1939). On the other hand, Fyke, Code, and Schlegel (1956) and Atkinson, Edwards, Honour, and Rowlands (1957) regard this region in man as a true sphincter. Nor is there general agreement on the effects brought about by stimulation of the extrinsic nerve supply to the region, although they have been repeatedly studied (Langley, 1898; May, 1904; Klee, 1919; Koennecke, 1922; Veach, 1925, 1926). Some experiments have suggested that the response of the sphincter is dependent upon the coexisting gastric tonus (Carlson et al., 1922; McCrea, McSwiney, and Stopford, 1925).

The present investigation defines the cardiac sphincter more accurately. The results of nerve

'Present address, Royal Infirmary, Aberdeen. stimulation and injected drugs suggest the mechanism of normal function. Opening of the cardiac sphincter can be induced either by increased oesophageal or gastric pressure. This effect is a function of the circular muscle fibres of the lower end of the oesophagus. Alterations in oesophageal and gastric pressure affect the sphincter both directly and reflexly.

\section{METHODS}

Male and female cats of 1.6 to $4.2 \mathrm{~kg}$. were used, having been allowed water, but no food, for 12 hours before the experiment. After induction with ethylchloride and ether, five were spinalized by the method of Kosterlitz, Krayer, and Matallana (1954), two were decerebrated, and 34 were anaesthetized with chloralose $(80 \mathrm{mg}$./kg.). Four animals were anaesthetized with sodium pentobarbitone (40 mg./kg.) by intraperitoneal injection.

In early experiments, a tube was passed through the pharynx into the oesophagus and a second tube was tied into a slit cut in the greater curvature of the stomach: these were each connected, via a reservoir, to separate water manometers. Either organ could be filled with saline and the pressure at which it emptied through the cardiac sphincter measured. The receiving organ, i.e., oesophagus or stomach, was allowed to drain freely at atmospheric pressure during such an experiment.

The region of the gastro-oesophageal junction was also directly observed (a) by tying a wide-bore glass tube into a slit in the greater curvature of the stomach, with its distal end overlying the junction; $(b)$ by using a cystoscope introduced in a similar way into the stomach; and (c) by observation of the oesophagus and stomach with the thorax and abdomen opened by a mid-line incision.

The lowest $2 \mathrm{~cm}$. of the oesophagus was later established as the region with sphincteric action. In some experiments, as illustrated in Fig. 1, this region was cut free from muscular and mucosal connexion with the rest 


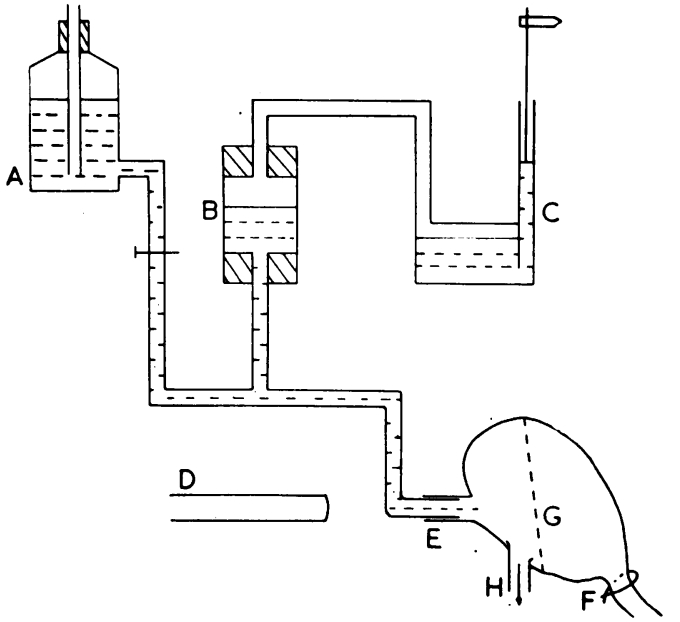

FIG. 1. Saline from a Mariotte bottle (A) flows at constant pressure through a tube inserted into the lower end of the oesophagus $(E)$ which is separated from the body of the oesophagus $(D)$. The vagi remain intact and are stimulated in the neck. The stomach is occluded at the pylorus $(F)$ but can be kept empty by the tube $(H)$. A mucosal barrier $(G)$ can be constructed so that the upper part of the stomach still remains empty and the remainder of the organ can be distended through another cannula tied in the greater curvature. Pressure changes in the lower oesophagus are transmitted to the reservoir $(B)$ and recorded by water manometer $(C)$ on a kymograph.

of the oesophagus by a transverse incision, taking care to preserve the extramural blood vessels and extramural nerve fibres. The lumen of the isolated segment was cannulated and connected to a Mariotte bottle of saline kept at a height of 20 to $40 \mathrm{~cm}$. above that of the oesophagus. A water manometer connected to a side arm measured the pressure at the point of inflow into the oesophageal segment. In this way the sphincter was used as a resistance to the free flow of saline $(5-30 \mathrm{ml} . / \mathrm{min}$., usually 10 $\mathrm{ml} . / \mathrm{min}$.) through the system and any change in tone was reflected as a change in the inflow pressure, contraction being registered as a rise in pressure. The saline drained into the stomach, which was kept empty by allowing free drainage through another cannula, to avoid pressure changes due to gastric contractions. The apparatus is shown in diagrammatic form in Fig. 1. The effect, on the isolated segment, of filling and emptying the main body of the oesophagus could also be studied in this preparation, as could the effects of nerve stimulation and injected drugs. By constructing a mucosal barrier (G) at the upper end of the stomach (Fig. 1) and inserting a second gastric cannula, the effect of distension of part of the stomach upon the tone of the sphincter was also investigated, without applying pressure directly to the sphincter itself.

The vagus nerves were stimulated in the neck using platinum electrodes, usually for periods of $30 \mathrm{sec}$. In order to stimulate the sympathetic supply the left gastric artery was divided and the distal end, along with the periarterial network of nerves, was pulled into a tubular polythene electrode holder in which two platinum rings spaced $0.5 \mathrm{~mm}$. apart acted as electrodes. Supra-maximal square wave shocks ( 20 volts) of $2 \mathrm{msec}$. duration, and frequencies varying from $1 / \mathrm{min}$. to $50 / \mathrm{sec}$. were provided by a stimulator.

DRUGS Intravenous injections of the following drugs (doses expressed as base) were given through a cannula tied in a femoral or jugular vein: acetylcholine chloride, physostigmine sulphate, adrenaline hydrogen tartrate and noradrenaline hydrogen tartrate, histamine hydrogen phosphate, 5-hydroxytryptamine creatinine sulphate, isopropylnoradrenaline sulphate, nicotine hydrogen tartrate, hexamethonium bromide, hyoscine hydrobromide, and atropine sulphate.

\section{RESULTS}

As it traverses the diaphragm, the oesophagus is surrounded by the phrenico-oesophageal ligament, which further applies the extrinsic nerves to its external surface. The whole is enveloped in a layer of pleura above the peritoneum below the diaphragm, yet the relations of the diaphragm are variable. The lower end of the oesophagus is mobile, and while the stomach is not normally pulled into the thorax, the extent of the intra-abdominal part of the oesophagus varies considerably in different animals and in the same animal at different times.

If the passage of saline from a Mariotte bottle through the oesophagus is observed with a cystoscope tied into the stomach and focused on the gastro-oesophageal junction, then at low pressures rhythmic opening and closing movements are observed. If the pressure of the perfusing fluid is raised, these rhythmic movements are still observed, though the orifice never completely closes. The appearances are those of a rosette-shaped structure of which the movements recall those of pupillary hippus. A similar picture is observed when the saline is forced through the sphincter from the gastric side: as the stomach fills, the gastric mucosa slides away from the rosette, which finally opens and rhythmic movements start. These appearances are unaltered by dividing the diaphragm and dissecting the surrounding ligamentous structures, provided the blood supply is not greatly disturbed.

OPENING PRESSURES OF THE SPHINCTER The pressure at which fluid can be maintained without leakage in either the oesophagus or stomach gives a measure of the resistance to opening of the sphincter. If the oesophagus is filled, increasing the pressure in $2 \mathrm{ml}$. steps, the pressure rises until the sphincter opens, and the oesophagus empties, though not completely. 
In spinal and decerebrate animals (seven experiments) this opening pressure was slightly higher $(14-20 \mathrm{~cm}$. $\mathrm{H}_{2} \mathrm{O}$ ) than in animals anaesthetized with chloralose $(8-12 \mathrm{~cm}$.). It was even lower $(3-6 \mathrm{~cm}$.) in four cats anaesthetized with nembutal. The sphincter closed again when the pressure had fallen to about half the opening pressure. This pattern, where a fairly high pressure was needed to open the sphincter, was observed in all but three animals (one spinal, two chloralose): in these, the opening pressure was only $2 \mathrm{~cm}$. of $\mathrm{H}_{2} \mathrm{O}$. The opening pressure in response to direct oesophageal distension in all animals was unaffected by removal of the surrounding diaphragmatic musculature.

Under the alternative conditions, testing the resistance of the sphincter to increase in intragastric pressure, the results were more varied. The pressure at which the sphincter opened in response to increased gastric pressure was always higher than that needed when tested from the oesophageal side of the sphincter. It was usually greater in animals anaesthetized with chloralose $\left(12-16 \mathrm{~cm} . \mathrm{H}_{2} \mathrm{O}\right)$ than in those anaesthetized with nembutal $\left(6-13 \mathrm{~cm} . \mathrm{H}_{2} \mathrm{O}\right)$. Dividing the diaphragm did not alter these opening pressures materially except in two animals. In one chloralose cat the pressure required to force the sphincter fell from 18 to $11.5 \mathrm{~cm}$. on dividing the diaphragm and in one nembutal animal it fell from $14.5 \mathrm{~cm}$. to $7 \mathrm{~cm}$.

It is obvious, therefore, that at the gastrooesophageal junction there exists a mechanism which resists the passage of fluid in either direction and which may be called a sphincter. The sphincter is always more powerful in resisting gastric reflux than in preventing oesophageal emptying. Its resistance is higher in spinal animals than in those anaesthetized with chloralose and even lower if nembutal is used. Occasionally, the diaphragm appeared to augment the resistance of the sphincter to gastric reflux but did not affect oesophageal emptying.

EFFECTS OF VAGOTOMY ON OPENING PRESSURES With the oesophagus, sphincter, and stomach in continuity, bilateral vagotomy in the neck did not alter the opening pressure measured from the oesophageal aspect, but almost invariably produced an increased resistance to pressure exerted in the stomach. With the sphincter separated from the body of the oesophagus, vagotomy abolished the response to oesophageal or gastric pouch distension. The opening pressures of the isolated sphincter, however, were similar to those found with the gut in continuity. Again it was found that vagotomy raised the gastric opening pressure, leaving the oesophageal opening pressure unchanged.
DEFINING THE SITE OF THE SPHINCTER Electrical stimulation of the vagus (see later) causes contraction of the body of the oesophagus and relaxation of the cardiac sphincter. If a saline-filled, wide-bore ( $8 \mathrm{~mm}$.) polythene tube is connected by a reservoir to a water manometer and has its tip situated in the midoesophagus it only records contractions of that part of the organ which is lower than the tip. A continuous flow of saline at about $10 \mathrm{ml} . / \mathrm{min}$. from a Mariotte bottle through the cannula results in a kymograph record of the alterations in pressure as the sphincter rhythmically contracts and relaxes. With the tip of the tube in this position vagal stimulation gives a contraction of the oesophagus which shows on the record as a sharp rise in pressure. As the tip of the tube is brought closer to the sphincter, a point is reached where stimulation results only in a pressure fall, due to relaxation of the sphincter. When the tube is advanced into the stomach, stimulation again results in contraction. Using the method where the sphincteric region is isolated from the other organs, these effects of vagal stimulation are even more strikingly demonstrated. Fig. 2 shows records of the pressure changes in the body of the oesophagus, the sphincteric segment, and the gastric pouch obtained simultaneously. The region where the response to stimulation is opposite to that of the body of the oesophagus and stomach is crudely defined as the lower $2 \mathrm{~cm}$. of the oesophagus. This is also the region which can be seen to remain tightly contracted if either the stomach or the oesophagus is filled with saline, as in the experiments where the opening pressure was measured. The sphincter no longer resists opening after the circular muscle fibres have been divided by an incision down to the mucosa. This incision does not encroach upon the gastric musculature. It should also be noted that the sphincter becomes completely incompetent within a minute of death of the animal.

REFLEXES ASSOCIATED WITH DISTENSION So far, the results indicate that the cardiac sphincter is normally closed, but that an increase in pressure on either side of it leads to leakage of fluid through it. This opening of the sphincter may have been brought about by one or more of several mechanisms: a local or a central reflex leading to an active relaxation, a direct response of the muscle fibres to the pressure change, or even by a simple physical distortion of the sphincter.

The possibility of a central reflex was investigated using the sphincteric region isolated from the body of the oesophagus, continuously perfused through its lumen with saline. A mucosal barrier across the stomach also enabled the effects of gastric distension to be observed. Even though there was no direct 


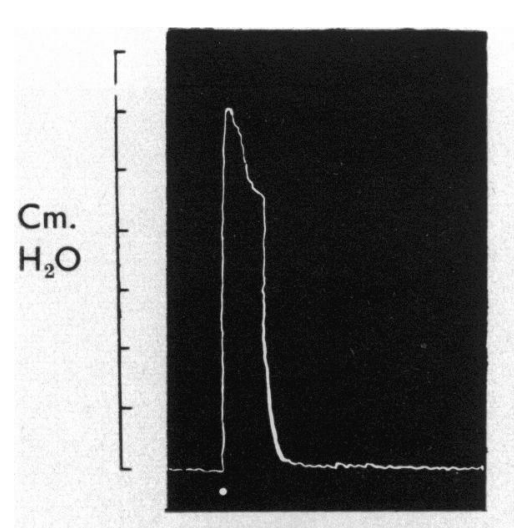

OES.

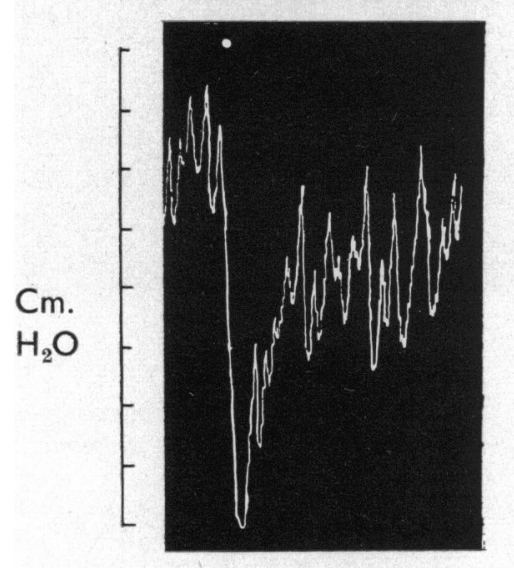

CARDIA

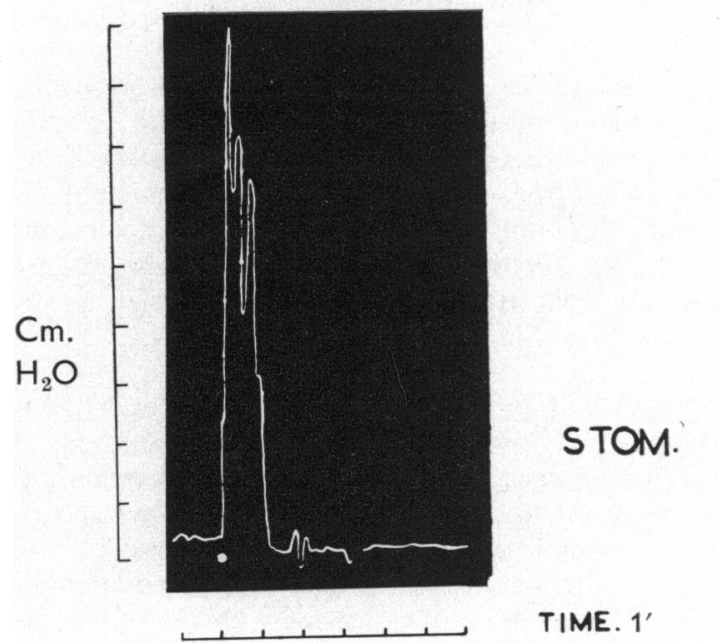

FIG. 2. Cat, $3.4 \mathrm{~kg}$. female, anaesthetized with chloralose. This record shows the effects obtained simultaneously from the body of the oesophagus, sphincter, and stomach pouch (isolated from the sphincter by a mucosal barrier) on stimulating the right cervical vagus nerve at 10 cycles per second for one minute. The centre record was obtained by perfusing the lumen of the sphincter with saline, as described in text. Time in minutes. muscular continuity, the cardiac sphincter relaxed when the oesophagus was distended with saline. The relaxation was roughly proportional to the amount of distension, was first seen in chloralose cats at an oesophageal pressure of $5 \mathrm{~cm}$. of water, and was immediate in onset (Fig. 3). Emptying the oesophagus resulted in a brief increase in the tone of the sphincter (Fig. 3b, 3c); if the oesophageal distension was maintained, the sphincter gradually recovered its tone (Fig. 3d).

Distension of the gastric pouch gave effects which depended in a different way upon the amount of distension. With volumes up to about $40 \mathrm{ml}$. (leading to an increased gastric pressure of 4-6 cm. $\mathrm{H}_{2} \mathrm{O}$ ) the tone of the sphincter increased, but with larger volumes, the increase in tone was quickly followed by a relaxation which became more and more dominant with further distension of the gastric pouch. Some recovery of tone took place while the pouch remained distended, but this was less than in the similar circumstance noted with persistent oesophageal distension. On emptying the stomach, the sphincter became briefly hypertonic, and subsequently recovered its normal tone. These effects were diminished by unilateral and abolished by bilateral vagotomy, performed in the neck.

EFFECTS OF NERVE STIMULATION The effect of stimulating the vagus and sympathetic nerves was tested on the sphincter isolated from the oesophagus. If the central end of the right vagus, divided in the neck, was stimulated, the left nerve being intact, no appreciable response was obtained until the frequency was raised to $1 / \mathrm{sec}$. At frequencies of $1 / \mathrm{sec}$. to $50 / \mathrm{sec}$., the sphincter relaxed, an effect which was delayed in onset at the lower frequencies. The degree of relaxation was maximal and the onset immediate at frequencies of 10 to 20 per sec. All these responses were abolished by cutting the contralateral vagus in the neck.

The peripheral end of the right vagus was stimulated at similar frequencies, and, again, only frequencies of $1 / \mathrm{sec}$. to $50 / \mathrm{sec}$. gave regular results. The character of the response obtained was not altered by the integrity of the other vagus. Relaxation of the sphincter, the normal response, was maximum at frequencies of 5 to 10 per sec. At higher frequencies, the response did not increase in magnitude but was sometimes more prolonged. At lower frequencies the response was smaller and there was often a delay in the onset of relaxation, or even a brief contraction preceding it (Fig. 4). Hexamethonium bromide in small doses $(0.5 \mathrm{mg}$. intravenously) abolished both the early contractions and the delay, suggesting that it may be due to a balance between contractile and dilator elements, and in larger doses $(10 \mathrm{mg} . / \mathrm{kg}$.) 
a

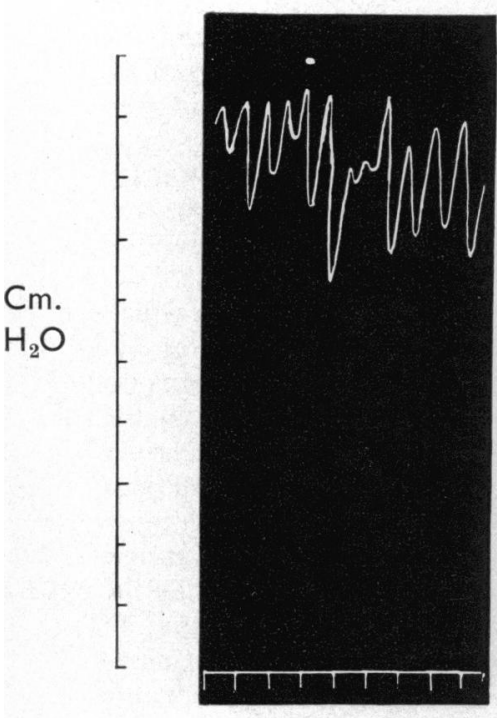

b

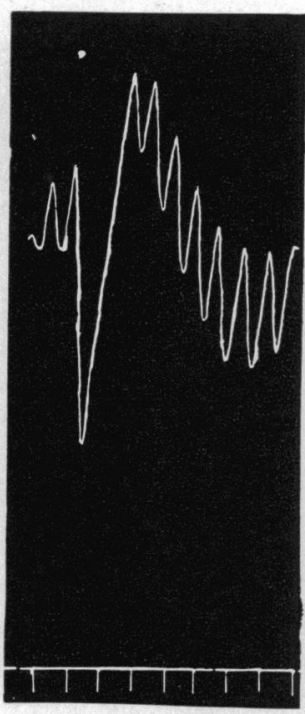

c

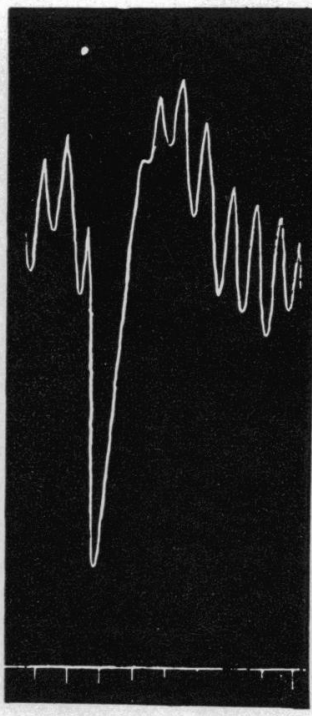

d

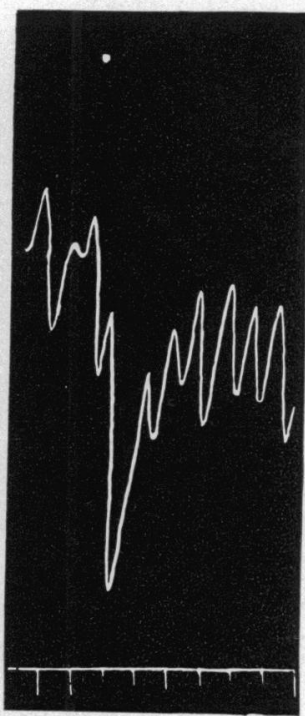

Oesophageal volume $(\mathrm{ml}$.

FIG. 3. Cat, $3.2 \mathrm{~kg}$. female, anaesthetized with chloralose. This records the effect obtained by the continuous flow method in the isolated sphincter of distending the body of the oesophagus. Only the vagus nerves connect the tissues. The oesophagus was filled rapidly and emptied after one minute (two minutes in d).

The response obtained is relaxation of the sphincter, the degree depending on the volume of saline introduced. Relaxation is followed by an increase in tone of the sphincter when the oesophagus is emptied after one minute but this does not occur if emptying is delayed $(d)$. Pressure changes in $\mathrm{cm} . \mathrm{H}_{2} \mathrm{O}$, time scale one minute.

entirely abolished all responses. Atropine (0.5 mg. intravenously) also abolished first the delay preceding relaxation and eventually $(2 \mathrm{mg} . / \mathrm{kg}$.) the entire response.

Division of one cervical vagus nerve had no effect on the intrinsic tone of the sphincter judged by the method of continuous flow, although bilateral vagotomy raised the tone, usually for two to three minutes, and occasionally for up to 30 minutes. However, when tested from the gastric side of the sphincter it was found that unilateral vagotomy raised the opening pressure from 12 to about $14 \mathrm{~cm}$. $\mathrm{H}_{2} \mathrm{O}$ and bilateral vagotomy raised it further to about $18 \mathrm{~cm} . \mathrm{H}_{2} \mathrm{O}$ (six out of seven animals.) This rise in tone persisted for the remainder of the experiment, a period varying up to three hours later.

The final path of the main sympathetic nerve supply to the cardiac sphincter is along the blood vessels to this structure. The major blood supply is from the oesophageal branch of the left gastric artery. Stimulation of these periarterial nerves entails division of the left gastric artery which produces an alteration in the rhythmic movements of the sphincter, slightly lowering the tone. It does not, however, abolish the resistance offered to perfusion. Stimulation of the sympathetic gave rise to substantial contractions of the sphincter, followed by an after-relaxation. This response was unaltered by hexamethonium $(5 \mathrm{mg} . / \mathrm{kg}$.). The effect of atropine ( $2 \mathrm{mg}$. $/ \mathrm{kg}$.) or hyoscine $(2 \mathrm{mg}$./ $/ \mathrm{kg}$.) was to abolish the after-relaxation and to reduce the size of the contraction (Fig. 5).

EFFECT OF DRUGS ON THE CARDIA Acetylcholine (1-100 $\mu \mathrm{g}$. intravenously) contracts the main body of the oesophagus and this is also its effect on the stomach. At the sphincter, relaxation always occurs, and a substantial effect is noted with doses of 5 to $10 \mu \mathrm{g}$. intravenously. The effect is potentiated by small doses of physostigmine $(10-15 \mu \mathrm{g}$. intravenously), abolished by hyoscine (2-10 mg. intravenously), or atropine (2-10 mg. intravenously), and unaffected by hexamethonium (up to $25 \mathrm{mg}$. intravenously).

Adrenaline and noradrenaline (1-500 $\mu \mathrm{g}$. intravenously) do not differ in their effects. An attempt was made to find if either drug was more active than the other but there was no apparent difference in the 


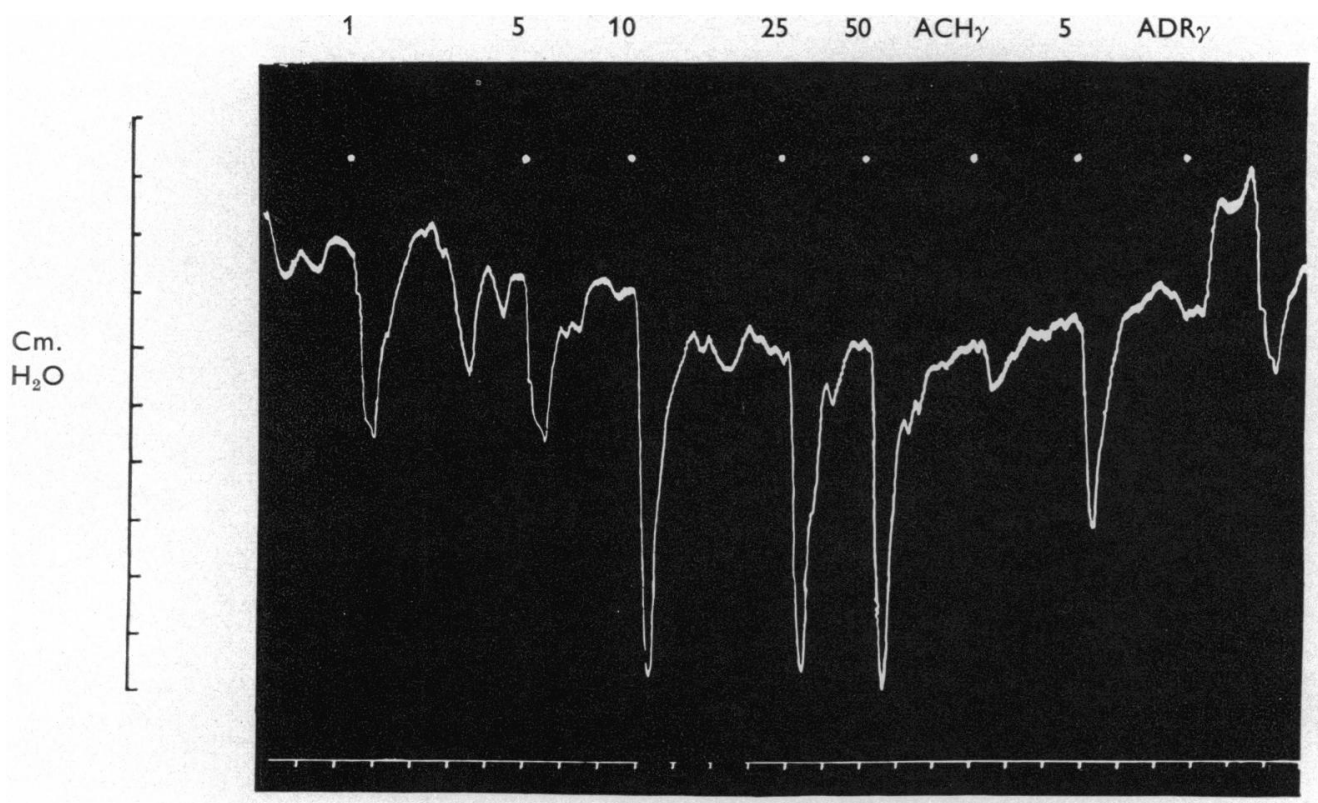

Lower

1

5

10

25

50
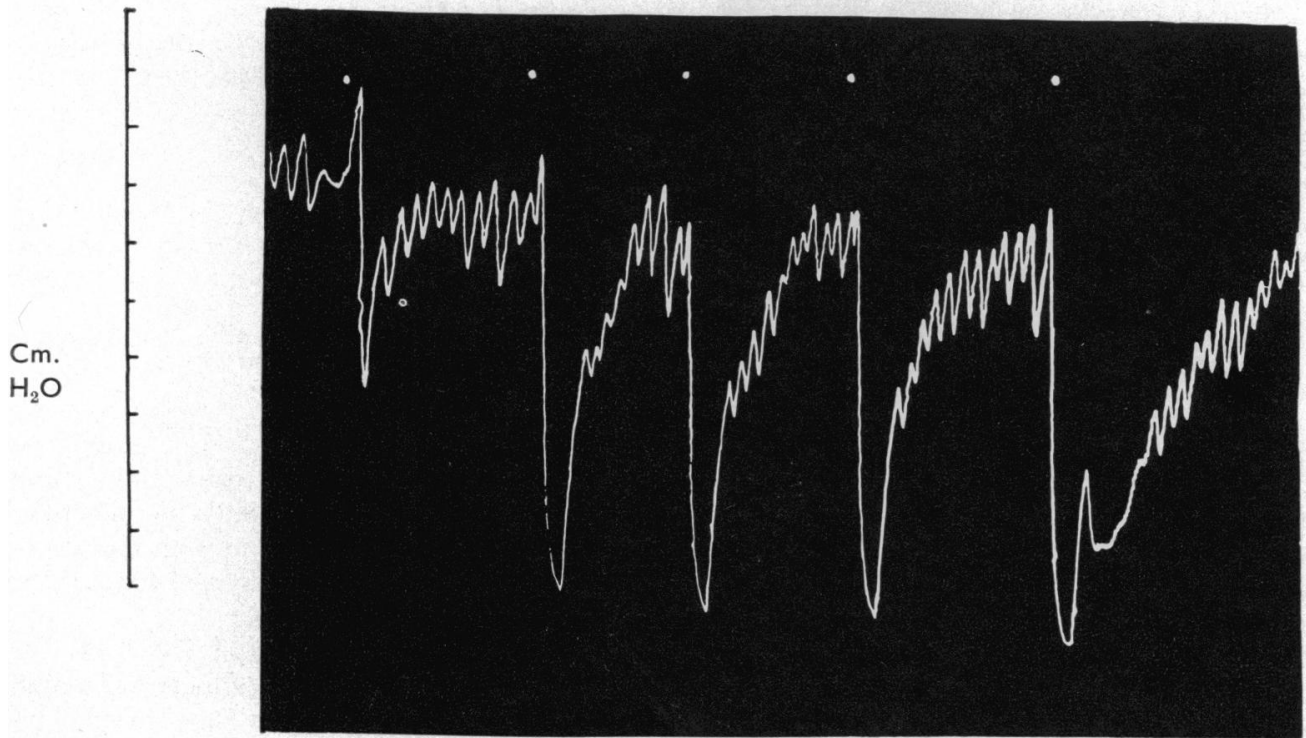

Upper

FIG. 4. Cat, $3.6 \mathrm{~kg}$. male, anaesthetized with chloralose. The upper tracing shows the effect on the isolated sphincter, continuously perfused from the oesophageal aspect, of peripheral vagal nerve stimulation in the neck at frequencies of $1 / \mathrm{sec}$. to 50/sec. for $30 \mathrm{sec}$. The lower record shows the effects obtained when the direction of perfusion is reversed. The effects of acetylcholine $(1 \mu \mathrm{g}$. and $5 \mu \mathrm{g}$. intravenously) and adrenaline $(5 \mu \mathrm{g}$. intravenously) are also noted. Pressure changes in $\mathrm{cm} . \mathrm{H}_{2} \mathrm{O}$, time in minutes. 


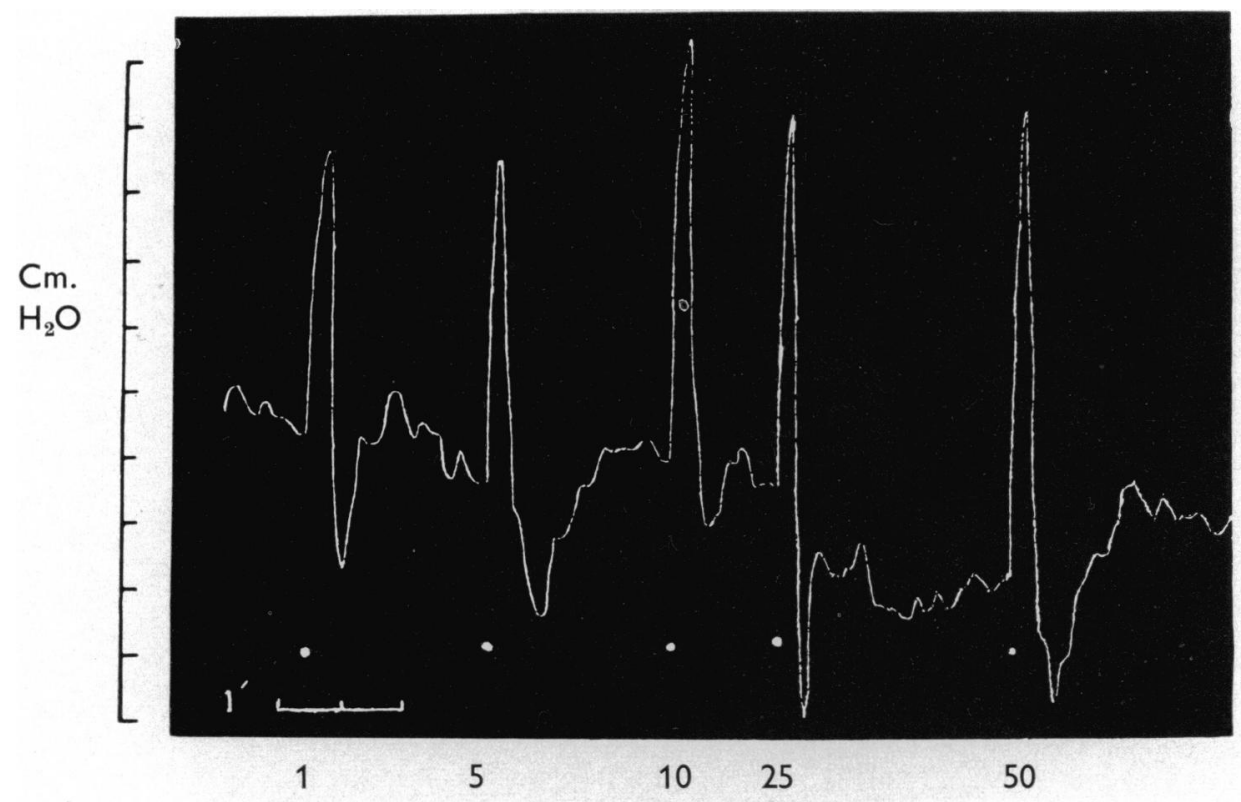

(a)

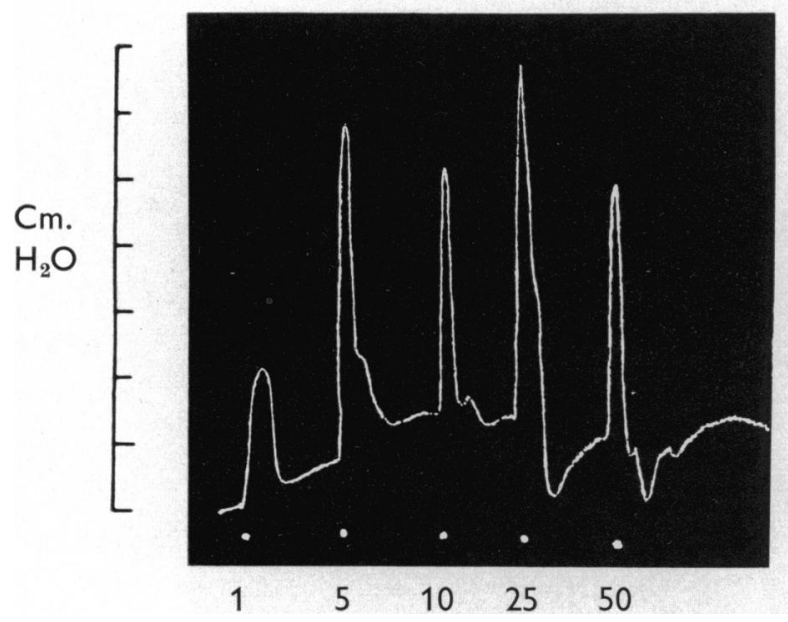

FIG. 5. Cat, $2.6 \mathrm{~kg}$. male, anaesthetized with chloralose. The record shows the effects of sympathetic nerve stimulation on the continuously perfused sphincter (a) before and (b) after atropine $5.4 \mathrm{mg}$. intravenously. The stimulus is applied for 30 sec.; pressure change in $\mathrm{cm}$.

(b) $\mathrm{H}_{2} \mathrm{O}$, time in minutes.

potencies. The sphincter contracts at low dosage (5-10 $\mu \mathrm{g}$.), and at larger doses a state akin to spasm results. It was also noted that in animals where normal rhythmic movements had become sluggish towards the end of an experiment, either drug would restore a period of brisk alternate contraction and relaxation. Histamine (1-500 $\mu \mathrm{g}$. intravenously) and 5-hydroxytryptamine (5-500 $\mu \mathrm{g}$. intravenously) also contracted the sphincter and restored rhythmicity.

Nicotine (50-100 $\mu \mathrm{g}$. intravenously) produced relaxation of the sphincter (Fig. 6), though a sustained contraction was noted on one occasion. Hexamethonium (10 mg. intravenously) caused a general decrease in tone which recovered within $5 \mathrm{~min}$. and also reduced substantially the effects of nicotine. This was always coincident with the fall in blood pressure, but rhythmic changes of tone of the sphincter were not affected (Fig. 6).

Hyoscine and atropine had little effect on the rhythmic variations in tone of the sphincter, although occasionally after atropine tone was briefly increased. The effect appeared similar to that sometimes seen after vagotomy and was of the same duration. While the relaxation produced by acetylcholine $(5 \mu \mathrm{g}$. intravenously) could readily be abolished by either hyoscine or atropine $(500 \mu \mathrm{g}$. 


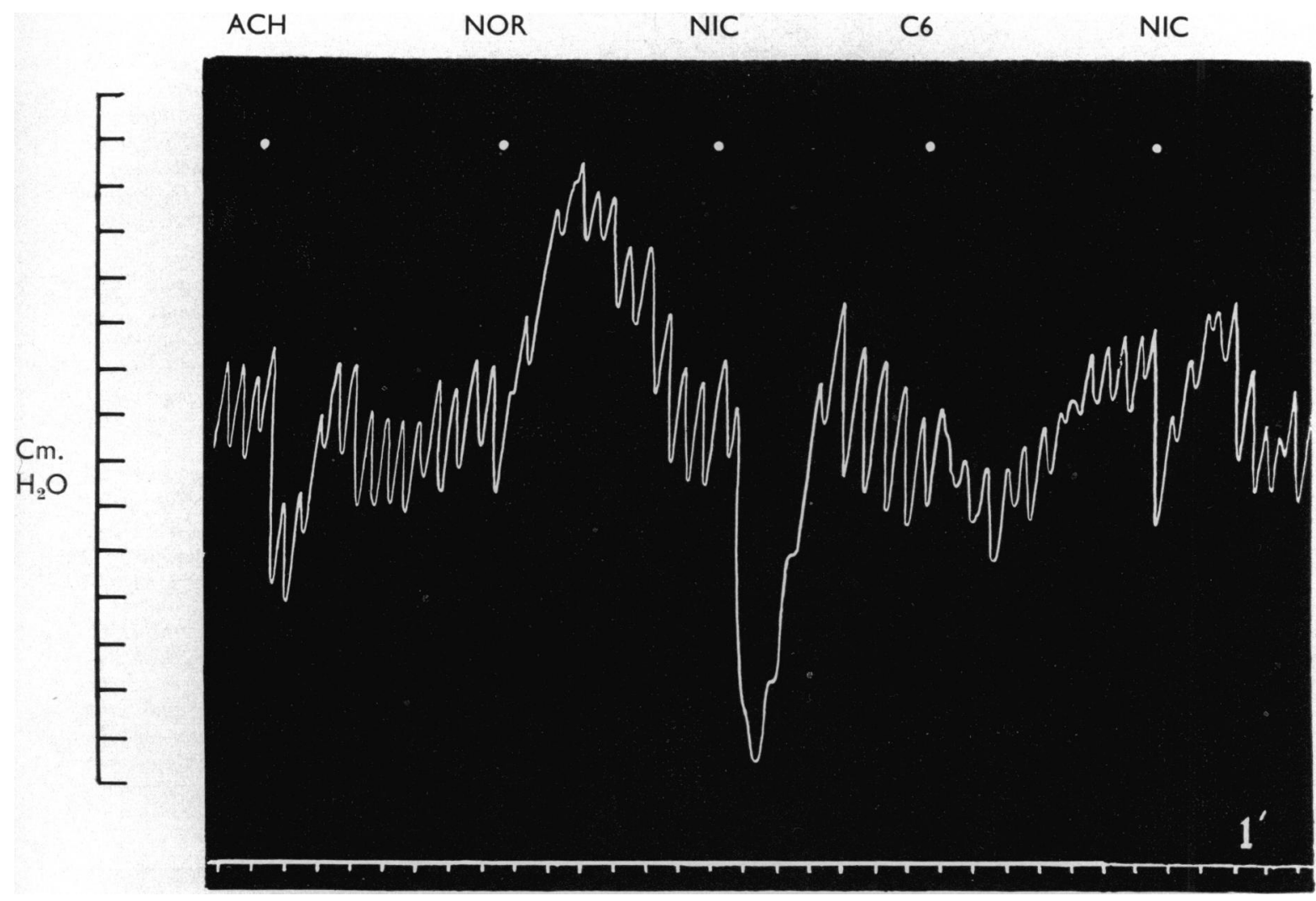

FIG. 6. Cat, $1.8 \mathrm{~kg}$. female, anaesthetized with chloralose. This record shows the effect of acetylcholine (5 $\mu$ g. intravenously), noradrenaline (10 $\mathrm{\mu g}$. intravenously), and nicotine (100 $\mathrm{\mu g}$. intravenously); hexamethonium (10 mg. intravenously) results in a small decrease in tone, after which the effect of nicotine is considerably reduced. Pressure change in $\mathrm{cm} . \mathrm{H}_{2} \mathrm{O}$, time in minutes.

intravenously), large doses (5-10 mg. intravenously) were required to abolish the effects of vagal stimulation.

Isopropylnoradrenaline (Fig. 7) was the only other drug which produced regular relaxation of the cardia, a dose of $50 \mu \mathrm{g}$. intravenously completely abolishing both the sphincteric action and fluctuations in tone for several minutes. The relaxation produced by isopropylnoradrenaline was unaffected by atropine.

OTHER EFFECTS Cannon (1908) postulated the theory of acid control of the cardiac sphincter and we investigated the effects of acid and alkali. If $\mathrm{HCl}$ is allowed to flow through the isolated sphincter, there is a gradual increase in tone as the concentration rises from $N / 100$ to $N / 10$. This increase in tone was not affected by bilateral vagotomy. At this concentration the cardia on one occasion, after a brief period of spasm, became completely incompetent and did not recover during the remaining three hours of experiment (Fig. 8).

Weak alkali $(\mathrm{N} \mathrm{NaHCO})_{3}$ ) slightly lowers the tone of the cardia and strong alkali $(\mathrm{N} / 10, \mathrm{NaOH})$ destroys it irreversibly. Ice-cold saline slightly increases tone. Isopropylnoradrenaline $(1-100 \mu \mathrm{g} . / \mathrm{ml}$.) and 5-hydroxytryptamine (50 $\mu \mathrm{g} .-1 \mathrm{mg} . / \mathrm{ml}$.) added to the perfusate were without effect.

An increase in tone of the sphincter was also seen if $\mathrm{N} / 10 \mathrm{HCl}(1-5 \mathrm{ml}$.) was injected into the saline in the isolated gastric pouch, but it was smaller than when the acid was applied directly to the mucous membrane of the sphincter and developed more slowly. It was unaltered by vagotomy.

\section{DISCUSSION}

So many different techniques have been used to study the cardiac sphincter, in so many different 

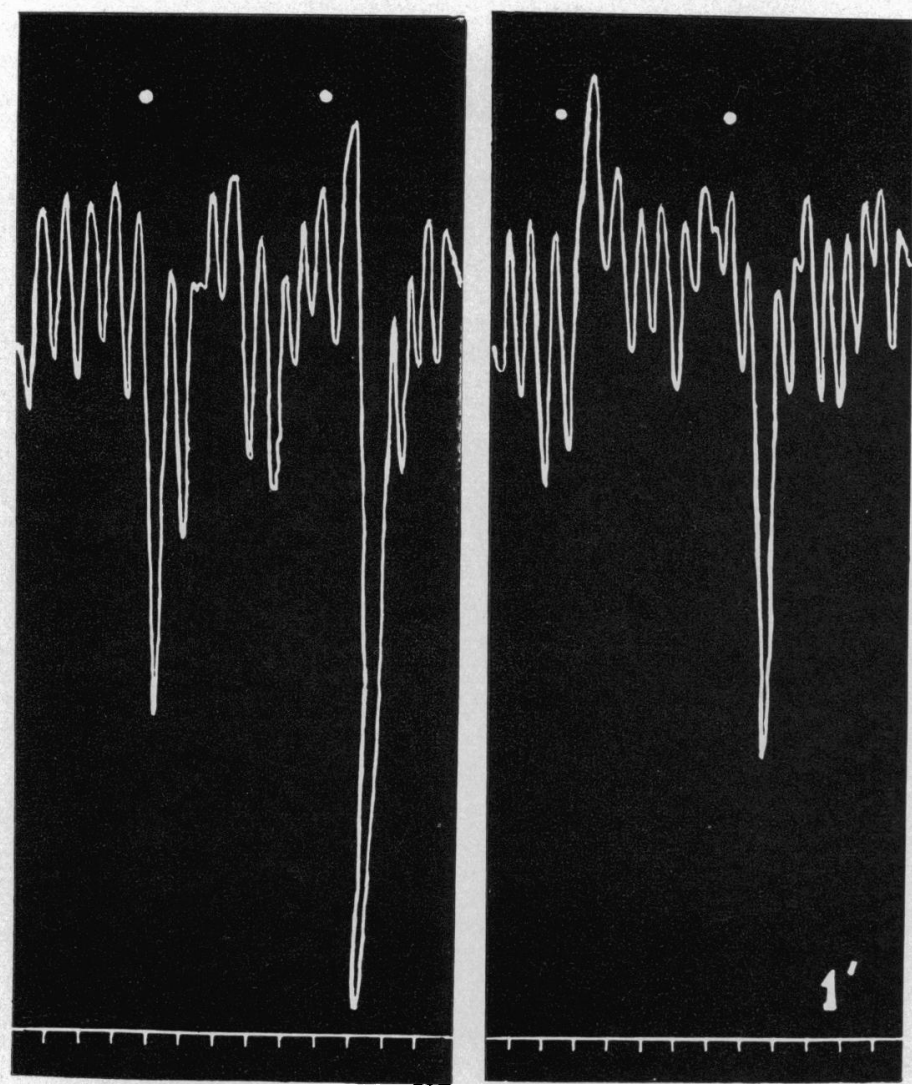

FIG. 7. Cat, $2 \cdot 8 \mathrm{~kg}$. maie, anaesthetized with chloralose. The record shows the effects of acetylcholine (5 $\mu g$. intravenously), vagal stimulation (5/sec. for $30 \mathrm{sec}$ ), adrenaline (5 $\mu \mathrm{g}$. intravenously) and isopropylnoradrenaline $(1$ $\mu g$. intravenously) on the cardia perfused through the lumen with saline. Pressure changes in $\mathrm{cm} . \mathrm{H}_{2} \mathrm{O}$, time in minutes.

FIG. 8. A. Cat, $3.6 \mathrm{~kg}$. male, anaesthetized with chloralose. The record shows the effect of perfusing the sphincter (isolated) with N/100 $\mathrm{HCl}$. The tone of the sphincter increases during the perfusion and quickly returns to normal when this is stopped.

B. Cat, $3.6 \mathrm{~kg}$. male, anaestinetized with chloralose. With $\mathrm{N} / 10 \mathrm{HCl}$ a brief spasm occurs after which the cardia becomes incompetent, and does not recover up to one hour.

Pressure changes in $\mathrm{cm} . \mathrm{H}_{2} \mathrm{O}$, time in minutes. The acid was injected into the side arm of the perfusing apparatus and the apparent delay in onset of the response represents the time taken for the acid to reach the sphincter.

FIG. 7 .

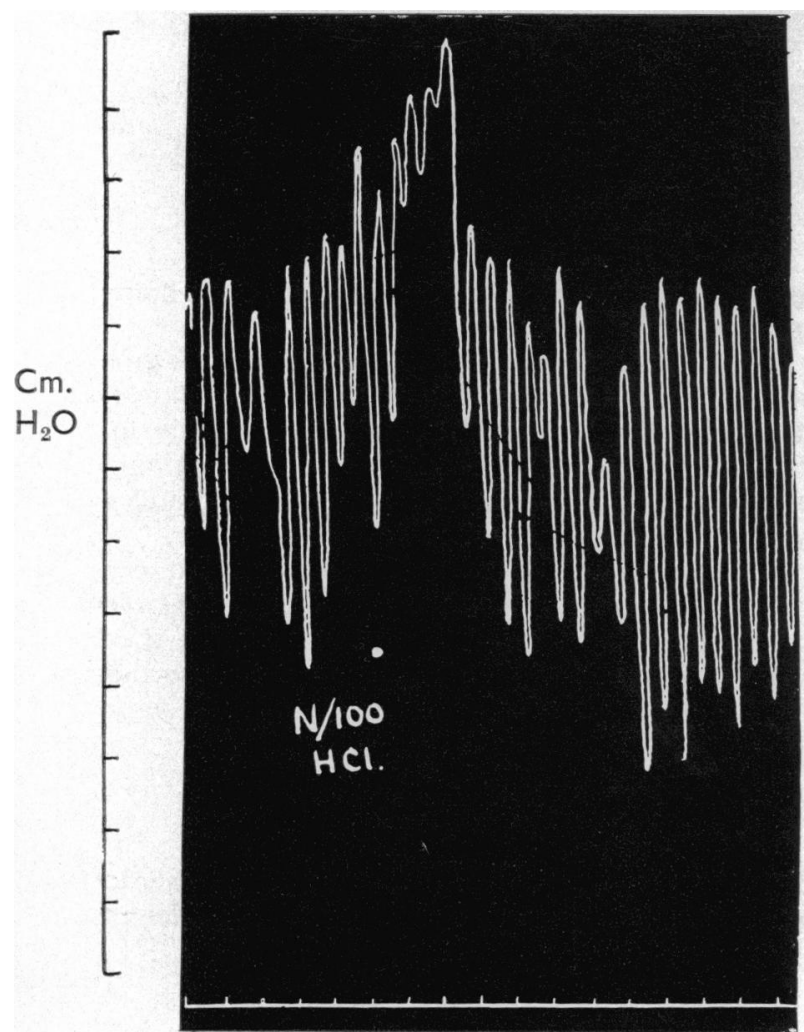

FIG. 8 A.

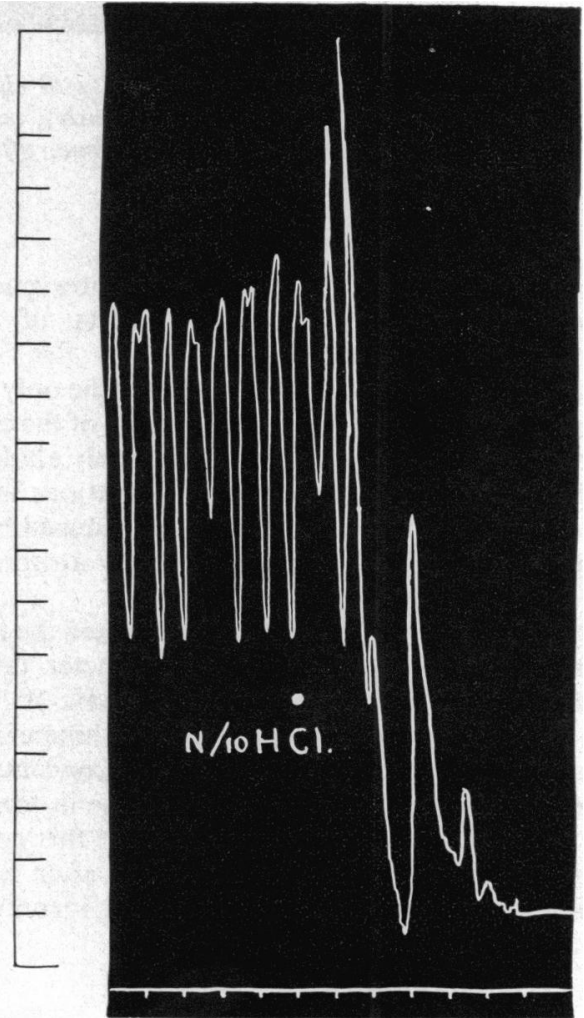

FIG. 8 B. 
species, that it is difficult to abstract a clear picture of the elements which contribute to and control its function. The anatomy of the lower end of the oesophagus in the cat is similar to that in man; we have therefore tried to assess by simple techniques the effects of various procedures on the functioning cardiac sphincter in the cat.

It was surprising to find that even the region with sphincteric action had not been clearly defined, so our first experiments were directed to this end. Mild distension of the oesophagus showed that the lower $2 \mathrm{~cm}$. remained tightly closed, whereas the rest of the organ expanded. The reactions of this last $2 \mathrm{~cm}$. were also different from those of the body of the oesophagus and from those of the stomach, so that it cannot be said to behave as part of the gastric musculature as suggested by Carlson et al. (1922) and by McCrea et al. (1925). The region of the sphincter comprises a longitudinal and circular muscle coat with mucous membrane containing the finely distributed muscularis mucosa. This muscularis in the cat contains only longitudinally disposed muscle fibres (Hughes, 1955). Whilst it has been shown that contraction of the longitudinal muscle of the oesophagus accompanies opening of the cardiac sphincter (Torrance, 1958), a substantial reduction in the amount of muscle available for this contraction by separation of the oesophagus from sphincteral region does not decrease the efficiency of the sphincter. The conclusion that the circular muscle fibres of the lower oesophagus are responsible for sphincteric actions seems inescapable, especially as the sphincter is destroyed by an incision dividing these fibres, an effect also shown to be possible in men (Atkinson et al., 1957).

It is clear that the sphincter resists the passage of fluid in either direction and that the 'normal' state of the organ is one of closure. When it is opened, during a continuous flow of fluid, rhythmic fluctuations in diameter can be seen. Immediately after killing the animal, the sphincter becomes completely incompetent.

All of our experiments point to the external nerve supply of the sphincter playing a major part in the control of its function. In the spinal cat, for instance, where reflexes through the higher centres are abolished, the pressure needed to open the sphincter was higher than in anaesthetized animals. Although our experiments have not excluded the possibility of a local reflex mechanism, a central reflex mediated by sensory and motor nerves in the vagi has been demonstrated. Stimulation of either the central or peripheral ends of a vagus nerve leads to dilatation of the sphincter. Distension of the oesophagus leads to the immediate opening of the cardiac sphincter, even when muscular continuity is absent, and this effect is abolished by vagotomy in the neck. A similar reflex in dogs was shown to follow oesophageal distension by Grondahl and Haney (1940) and in man to accompany swallowing (Atkinson et al., 1957). It has also been shown by cineradiography that if contrast medium is introduced into the oesophagus through a Ryle tube, the human cardiac sphincter is able to support a column of fluid about $7 \mathrm{~cm}$. high without leakage, and that on making a 'dry' swallowing movement, the sphincter opens (Ardran, Clark, and Vane, unpublished observations).

Both these observations in humans and our present work in cats make it probable that the valvular nature of the cardiac sphincter, as discussed by Dornhorst et al. (1954), is a facet of the reflex control.

The effects of distension of the stomach on the tone of the cardiac sphincter were interesting, both in this respect and in relation to the function of the stomach as a storage organ. Moderate distension of the gastric pouch was accompanied by a tighter closure of the sphincter, but, with further distension, a stage was reached at which the sphincter relaxed. Both of these effects must also be reflex in nature for they are abolished by cervical vagotomy and are too prompt to be mediated by release of a hormone. Presumably, the initial increase in tone of the cardiac sphincter minimizes reflux of food into the oesophagus, but gross distension of the stomach reflexly opens the sphincter as a safety mechanism to prevent rupture of the stomach.

All of these reflexes were mediated through the vagus nerves and this may well be the major function of the vagal innervation. We obtained no evidence for a tonic vagal discharge to the sphincteric region in our experiments. Such a discharge would tend to keep the sphincter partially open but neither vagotomy nor the intravenous injection of atropine or hexamethonium led to more than a very brief increase in tone of the muscle. In fact, the only direct effect vagotomy seemed to have on the function of the sphincter was to increase slightly the resistance to gastric reflux, as was also found by Carlson et al. (1922), an effect probably linked with the abolition of the reflexes just discussed.

In only two of the many experiments did the integrity of the diaphragm appear to augment the sphincteric action and this was by aiding the prevention of gastric reflux. The more general lack of change of function of the sphincter on removal of the diaphragm agrees with the results of Botha (1958b), who concluded that in man the diaphragm might occasionally assist in preventing reflux but was not normally responsible for doing so. In our experiments, the two exceptions might have been 
brought about by inadvertent interference with the extrinsic innervation to the sphincter, but it should be mentioned that Shenk and Frederickson (1958) concluded that in the cat the diaphragm considerably augmented the ability of the sphincter to resist passage of fluid.

Direct nerve stimulation confirmed that the vagus supplies predominantly inhibitory and the sympathetic predominantly excitatory fibres to the sphincter. Mixed effects on vagal stimulation were only seen at low frequencies and may have been due either to the inclusion of a few muscle fibres from the stomach or oesophagus (which are contracted by vagal stimulation) or to a mixture of adrenergic and cholinergic nerves in the vagus, as suggested by Paton and Vane (1956). Either interpretation would be in accord with the views of McCrea et al. (1925), who found that the effect of vagal stimulation was dependent upon the resting tone of the sphincter. In a muscle with a low tonus, excitatory effects would show up best, but if the muscle is already contracted relaxation would predominate. Although Langley (1898) suggested that the nerves causing relaxation of the sphincter passed intramurally down the oesophagus and Lehmann (1945) confirmed this suggestion in the dog, there is no doubt that in the cat stimulation of the vagus produces relaxation of the cardiac sphincter irrespective of muscular continuity with the rest of the oesophagus.

The experiments with injected drugs all confirm the well-established views on the transmitters of nervous effects. Intravenous acetylcholine reproduced the inhibitory effects of vagal stimulation and atropine or hyoscine blocked both, though more was needed to block the vagal effects, a characteristic common to other sites in the gastrointestinal tract (Ambache, 1955). Similarly, the effects of sympathetic stimulation were mimicked by both adrenaline and noradrenaline, but not by isopropylnoradrenaline.

Finally, it was shown that a mechanism exists whereby acid can induce an increase in tonus in the cardiac sphincter when applied either to the mucosa of the stomach, as suggested by Cannon (1908), or to the mucous membrane of the sphincteric region itself. The mechanism by which this effect is brought about is uncertain.

We are grateful to the Dan Mason Research Foundation for generous financial assistance in the performance of this work. We wish to thank Mr. D. Green and his staff for technical assistance.

\section{REFERENCES}

Ambache, A. (1955). The use and limitations of atropine for pharmacological studies on autonomic effectors. Pharmacol. Rev., 7, 467-494.

Atkinson, M., Edwards, D. A. W., Honour, A. J., and Rowlands, E. N. (1957). Comparison of cardiac and pyloric sphincters. Lancet, 2, 918-922.

Barrett, N. R. (1954). Hiatus hernia. Brit. J. Surg., 42, 231-243.

Botha, G. S. Muller (1958a). A note on the comparative anatomy of the cardio-oesophageal junction. Acta anat. (Basel), 34, 52-58.

(1958b). Mucosal folds at the cardia as a component of the gastro-oesophageal closing mechanism. Brit. J. Surg., 45, 569-580.

Cannon, W. B. (1908). The acid closure of the cardia. Amer. J. Physiol., 23, 105-114.

Carlson, A. J., Boyd, T. E., and Pearcy, J. F. (1922). Studies on the visceral sensory nervous system. XIV. Arch. intern. Med., 30, 409-433.

Dornhorst, A. C., Harrison, K., and Pierce, J. W. (1954). Observations on the normal oesophagus and cardia. Lancet, 1, 695-698.

Fyke, F. E. Jr., Code, C. F., and Schlegel, J. F. (1956). The gastrooesophageal sphincter in healthy human beings. Gastroenterologia (Basel), 86, 135-150.

Grondahl, J. W., and Haney, H. F. (1940). Attempt to produce experimental cardiospasm in dogs. Proc. Soc. exp. Biol. (N.Y.), 44, 126-129.

Hughes, F. B. (1955). The muscularis mucosae of the oesophagus of the cat, rabbit, and rat. J. Physiol. (Lond.), 130, 123-130.

Klee, P. (1919). Beiträge zur patholegeschen Physiologie der Magerinnervation. Dtsch. Arch. klin. Med., 129, $204-241$.

Knight, G. C. (1934). The relation of the extrinsic nerves to the functional activity of the oesophagus. Brit. J. Surg., 22, 155-168.

Koennecke, W. (1922). Experimentelle Innervationsstörungen am Magen und Darm. Z. ges. exp. Med., 28, 384-412.

Kosterlitz, H. W., Krayer, O., and Matallana, A. (1954). The effect of moderately large doses of veratramine and veratrosine on the rhythm of the acutely denervated heart of the cat. J. Physiol. (Lond.), 124, 40P.

Langley, J. N. (1898). On inhibitory fibres in the vagus to the end of the oesophagus and stomach. Ibid., 23, 407-414.

Lehmann, G. (1945). Gastric cardiospasm in the dog. Amer. J. Physiol., 143, $163-168$.

Lendrum, F. C. (1937). Anatomic features of the cardiac orifice of the stomach, with special reference to cardiospasm. Arch. intern. Med., 59, 474-511.

May, W. P. (1904). The innervation of the sphincters and musculature of the stomach. J. Physiol. (Lond.), 31, 260-271.

McCrea, E. D. McSwiney, B. A., and Stopford, J. S. B. (1925). Effects of section of the vagi nerves on the motor activity of the stomach. Ibid., 60, XXIX-XXX.

Nauta, J. (1955). Een studie van het afsluitings-mechanisme tussen slokdarn en maag. Stenfert Kroese N.V., Leiden.

(1956). The closing mechanism of the cardia. Arch. chir. neerl., 8, 280-291.

Paton, W. D. M., and Vane, J. R. (1956). The responses of the isolated stomach of a guinea-pig to electrical excitation. Proc. XX Int. Physiol Congress, p. 709.

Roux, J. (1939). Le segment cardio-oesophagien. Bronchoscopie, pp. 81-113.

Shenk, E. A., and Frederickson, E. L. (1958). Oesophageal sphincter mechanisms. Fed. Proc., 17, 142.

Torrance, H. B. (1958). Studies on the mechanism of gastro-oesophageal regurgitation. J. roy. Coll. Surg. Edinb., 4, 54-62.

Veach, H. O. (1925). Studies on the innervation of smooth muscle. III. Splanchnic effects on the lower end of the oesophagus and stomach of the cat. J. Physiol. (Lond.), 60, 457-478.

(1926). Studies on the innervation of smooth muscle. IV. Functional relations between the lower end of the oesophagus and stomach of the cat. Amer.J. Physiol., 76, 532-537. 